\title{
Desain Wire Winding Machine Sebagai Alat Bantu Pembuatan Kabel Pemandu Stent Koroner
}

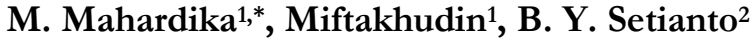 \\ 1Departemen Teknik Mesin dan Industri, Fakultas Teknik, Universitas Gadjah Mada \\ Jalan Grafika No. 2 Yogyakarta 55281 Telp. +62-274-521673 \\ 2Departemen Kardiologi dan Kedokteran Vaskular, Fakultas Kedokteran, Kesehatan Masyarakat dan Keperawatan, \\ Universitas Gadjah Mada, Jalan Farmako Sekip Utara,Yogyakarta 55281 Telp. +62 274560300 \\ e-mail: *1muslim_mahardika@ugm.ac.id
}

\begin{abstract}
Abstrak
Guide wires (kabel pemandu) merupakan perangkat pendukung utama untuk melakukan operasi pada lumen (pipa pembuluh darah), pemasangan stent koroner atau ring organ jantung, serta pada operasi urology. Perangkat ini berfungsi sebagai pemandu dan pembawa agar dapat mencapai pembuluh darah yang mengalami penyempitan atau penyumbatan karena penimbunan plak. Sejak guide wire diperkenalkan pada tahun $1980 \mathrm{an}$, pemasangan stent koroner pada pasien bisa dilakukan tanpa pembedahan. Kebutuhan stent koroner yang begitu besar di Indonesia dan semua perangkat tersebut merupakan produksi luar negeri (impor), memunculkan dorongan untuk mengkaji dan memproduksi peralatan-peralatan ini terlebih guide wire, sehingga dapat mengurangi ketergantungan pada peralatan impor tersebut. Pada penelitian ini, wire winding machine didesain dengan menggunakan software CAD dan analisis numerik kemudian dilakukan. Hasil analisis numerik pada mesin didapatkan bahwa tegangan maksimum pada model wire winding machine adalah sebesar 20,9 $\mathrm{MPa}$, faktor keamanan minimum pada model mesin, yaitu sebesar 11,93, dan nilai displacement yang terjadi pada wire winding machine adalah sebesar $0,435 \mathrm{~mm}$.
\end{abstract}

Kata kunci: perancangan, wire winding machine, analisis tegangan, guide wire.

\begin{abstract}
Guide wires are the main supporting devices for lumen surgery, installation of coronary stent, as well as in urology surgery. This device functions as a guide and carrier to reach blood vessels which experience constriction or blockage due to plaque buildup. Since the introduction of guide wire the 1980s, the installation of a coronary stent in patients can be done without surgery. The large demand of coronary stent in Indonesia and all is supporting devices are still being imported, giving rise to the urge to study and produce all these devices, especially guide wire, so it can reduce those imported product. In this study, the wire winding machine was designed by using CAD software and the numerical analysis was carried out. The results of numerical analysis on the machine showed that the maximum stress in the wire winding machine model is $20.9 \mathrm{MPa}$, the minimum safety factor in the engine model is 11.93, and the displacement value that occurs in the wire winding machine is $0.435 \mathrm{~mm}$.
\end{abstract}

Keywords: design, wire winding machine, stress analysis, guide wire. 


\section{PENDAHULUAN}

Kabel pemandu (guide wires) merupakan perangkat pendukung utama untuk melakukan operasi pada lumen (pipa pembuluh), pemasangan stent koroner atau cincin pada organ jantung, serta untuk penanganan kelainan urology. Penyakit jantung saat ini menempati posisi tertinggi sebagai penyebab kematian di dunia, dan berdasarkan diagnosis dokter prevalensi penyakit jantung koroner di Indonesia tahun 2013 sebesar 0,5\% atau diperkirakan sekitar 883.447 orang, sedangkan berdasarkan diagnosis dokter, gejala penyakit jantung sebesar 1,5\% atau diperkirakan sekitar 2.650.340 orang (Kementerian Kesehatan RI, 2013). Salah satu solusi umum yang digunakan dokter-dokter saat ini adalah dengan melakukan operasi pemasangan stent pada organ jantung(Sell-Le Blanc, Hofmann, Simmler, \& Fleischer, 2016; Vijayvergiya \& Gupta, 2017; Zou et al., 2016). Penelitian menyatakan bahwa sejak awal setelah diperkenalkan pada tahun 1980an, stent koroner (coronary stent) banyak pasien dan dokter spesialis yang cenderung lebih suka melakukan operasi dengan pemasangan stent koroner dibandingkan dengan operasi pembedahan.

Dalam pemasangan stent terdapat perangkat pendukung utama berupa guide wire (kabel pemandu) yang akan membawa stent jantung (koroner) agar dapat mencapai pembuluh darah (atherosclerosis) yang mengalami penyempitan atau penyumbatan karena penimbunan plak. Saat ini semua perangkat pemasangan stent koroner merupakan produksi luar negeri (impor). Hal tersebut memunculkan dorongan untuk mengkaji stent koroner terlebih guide wire dan membuat suatu wire winding machine yang dapat memproduksi guide wire di dalam negeri sendiri sehingga dapat menggantikan ketergantungan perangkat dari luar negeri. Wire winding machine sendiri berupa mesin yang memiliki satu fungsi utama yaitu penggulungan beberapa kabel atau benang menjadi satu kabel yang fleksibel tetapi kokoh. Dengan beberapa kombinasi mesin konvensional yakni winding machine, serta drill dan tambahan metode permesinan brazing sehingga dapat membuat guide wire. Guide wire dibuat dari material biokompatibel, seperti stainless steel 316L dan titanium, dapat memenuhi kebutuhan guna pemasangan stent koroner dari dalam negeri. Manufaktur komponen mesin pembuat guide wire bisa menggunakan permesinan non konvensional dengan aplikasi kecerdasan buatan (Mahardika, 2005; Sudiarso \& Mahardika, 2016)

Dari latar belakang tersebut, didapat suatu permasalahan yang akan dijawab pada makalah ini, yaitu rancang bangun prototype wire winding machine yang nantinya dapat digunakan untuk membuat struktur guide wire stent koroner. Dalam makalah ini juga dibandingkan bentuk fisik wire winding machine produk sendiri dengan produk impor yang telah ada.

\section{METODE PENELITIAN}

Wire winding machine merupakan mesin penggulung kawat yang mana menggunakan dua prinsip mesin perkakas yang digabungkan menjadi satu, yakni mesin bubut dan drilling. Penggabungan sistem dari mesin-mesin perkakas tersebut digerakkan oleh dua motor DC brushed serta satu buah motor stepper. Alat ini dibuat dengan menggunakan bahan biokempatibel berupa sebuah kawat titanium yang dijepit kedua ujungnya, kemudian kawat stainless steel 316L yang dililitkan sebagai selubung core wire guide berupa kawat titanium tadi. Motor stepper digunakan sebagai penggerak point of pay off dari penyuplai kawat stainless steel 316L sesuai dengan jalur yang ada, sehingga didapatkan gulungan yang lurus dan rapat. Kontrol dari keluaran potensiometer sebagai pengatur kecepatan motor (PWM) baik untuk motor DC dan motor stepper digunakan untuk menyesuaikan panjang dan kerapatan dari lilitan kawat. Setelah 
ukuran guide wire yang diinginkan telah terpenuhi mesin akan berhenti beroperasi, dengan kondisi kedua ujung lilitan akan tetap terjepit pada chuck. Kemudian dilakukan proses lanjut berupa brazing di ujung-ujung guide wire sehingga material core/inti akan bersatu. Sebagai langkah akhir setelah kedua ujung dilepas dari chuck wire winding machine, ujung guide wire tersebut akan dikenai proses manufaktur non-konvensional berupa electropoilishing agar mendapatkan bentuk round nose/ujung yang bundar serta sangat halus. Pada penelitian ini belum dibahas tentang proses brazing dan electropoilishing.

\section{HASIL DAN PEMBAHASAN}

Hasil rancangan wire winding machine ini terbagi dalam dua modul utama. Modul tersebut adalah modul rangka utama dan modul sistem wire winding supply. Rancangan wire winding machine ini terdiri dari beberapa jenis dengan jumlah total part adalah 19 buah. Berikut rancangan frame untuk wire winding machine, seperti tertera pada Gambar 1.

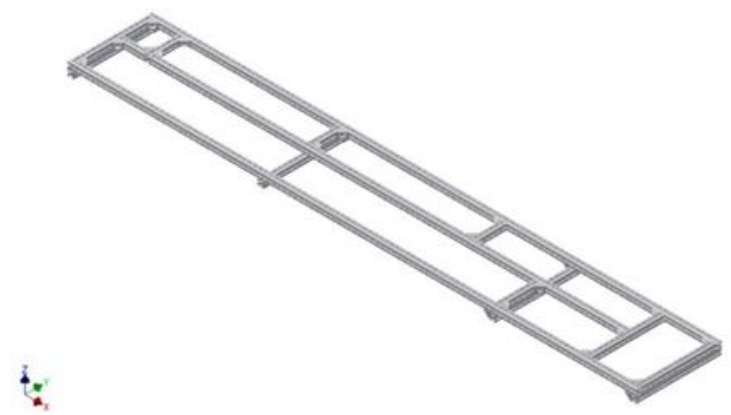

Gambar 1. Frame untuk wire winding machine

Selanjutnya dengan menggunakan tombol mesh view dapat terlihat susunan mesh pada model desain wire winding machine yang disimulasikan, seperti yang terlihat pada Gambar 2. Dapat diamati bahwa model ini menggunakan elemen berjumlah 1.321 .149 buah dan nodes berjumlah 2.310 .842 buah.

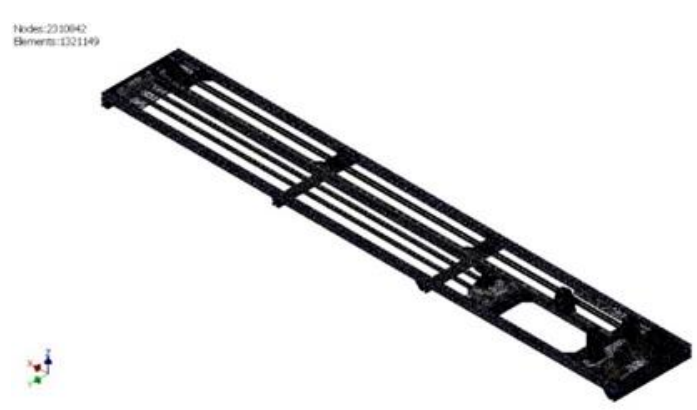

Gambar 2. Frame meshing untuk wire winding machine

Setelah desain selesai dibuat maka perlu dilakukan simulasi pengujian untuk mengetahui apakah desain yang dibuat masih bisa dan aman menahan gaya-gaya yang bekerja pada desain wire winding machine ini. 


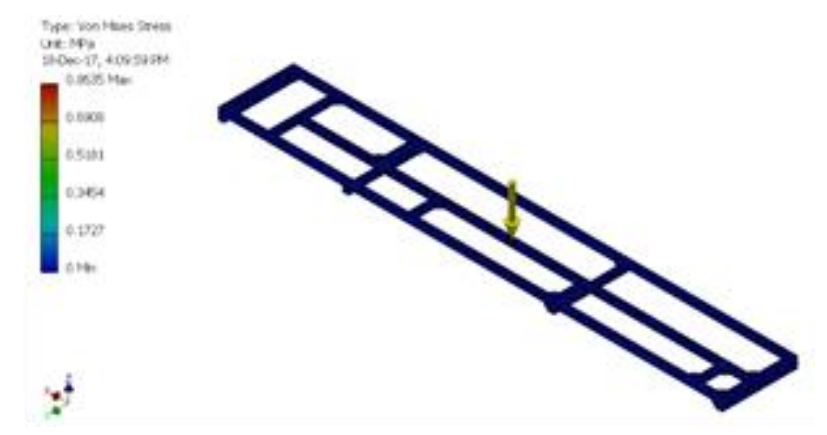

Gambar 3. Hasil Stress Analysis tipe Von Mises Stress Rangka Utama

Simulasi FEA dilakukan dengan menggunakan software CAE dengan tipe tegangan $V$ on Mises Stress, safety factor, dan analisiss displacement. Data tersebut didapat dengan cara memberikan gaya pada shaft manipulator reel wire supply dengan nilai yang didapat berdasarkan berat komponen sesuai dengan desain. Hasil dari simulasi dapat dilihat pada Gambar 3 dan 4.

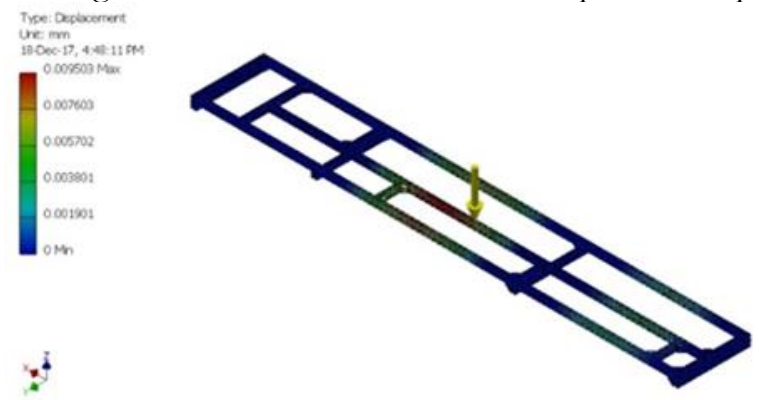

Gambar 4. Hasil Stress Analysis tipe Displacement Rangka Utama

Dari hasil simulasi stress analysis baik pada shaft manipulator reel wire supply maupun rangka utama dapat dilihat bahwa yang mengalami displacement dan nilai Von Misses Tegangan paling tinggi yang berada pada bagian shaft manipulator reel wire supply yakni komponen linier bearing LM12. Hasil simulasi didapat nilai Von Mises Stress sebesar 0,86 MPa dan nilai displacement 0,009 mm pada shaft berbahan stainless steel 440C.

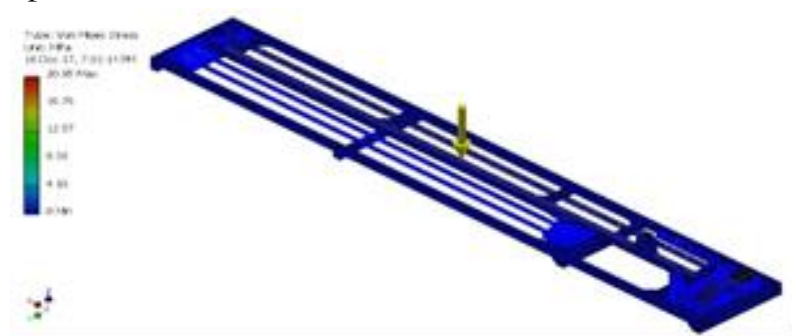

Gambar 5. Analisa elemen hingga untuk assembly wire winding machine secara utuh

Berdasarkan hasil simulasi tipe Von Mises Stress tersebut diketahui bahwa besarnya nilai tegangan terbesar yang terjadi pada desain shaft manipulator reel wire supply ini sebesar 0,86 $\mathrm{MPa}$ dimana masih berada dibawah nilai yield strength dari bahan steel alloy yang digunakan sebesar $250 \mathrm{MPa}$. Displacement juga terlihat tidak memengaruhi struktur yaitu dengan displacement sebesar 0,009 $\mathrm{mm}$, sehingga dapat dipastikan bahwa desain ini cukup kuat. 
Sedangkan pada analisa elemen hingga untuk assembly wire winding machine secara utuh dari aspek analisis tegangan Von Mises (20,95 MPa), dapat diamati pada Gambar 5, dan masih aman karena masih dibawah $250 \mathrm{MPa}$.

\section{KESIMPULAN}

Desain dan manufaktur dari wire winding machine pada penelitian ini menunjukkan kaberhasilannya sebagai sebuah mesin prototipe untuk memproduksi guide wire sendiri. Dengan hasil simulasi Finite Element Analysis pada mesin didapatkan bahwa tegangan maksimum pada model wire winding machine adalah sebesar 20,9 MPa. Dari informasi ini maka dapat diketahui safety factor minimum pada model mesin, yaitu sebesar 11,93. Selain itu didapatkan nilai displacement yang terjadi pada wire winding machine saat proses memanufaktur adalah sebesar $0,435 \mathrm{~mm}$. Dari analisis tersebut, wire winding machine ini dapat dikatakan layak sebagai prototipe mesin pembuat guide wire produksi dalam negeri.

\section{DAFTAR PUSTAKA}

Mahardika, M. (2005). Neural Network Prediction of Cutting Tool Wear During Turning Operation. University of Malaya.

Sell-Le Blanc, F., Hofmann, J., Simmler, R., \& Fleischer, J. (2016). Coil winding process modelling with deformation based wire tension analysis. CIRP Annals - Manufacturing Technology, 65(1), 65-68. https://doi.org/10.1016/j.cirp.2016.04.037

Sudiarso, A., \& Mahardika, M. (2016). Advanced Machining Processes (Non-Conventional) (UGM Press, Yogyakarta.). Retrieved from https://books.google.co.in/books?hl=en\&lr=\&id=do5SDwAAQBAJ\&oi=fnd\&pg=PP 13\&dq= $\% 22 \mathrm{EDM} \% 22+\% 22$ rotary+electrode $\% 22 \&$ ots=ldgW8CtfLb\&sig=lFQ37fxoo BuEOJlur9mgKB-ba7Y

Vijayvergiya, R., \& Gupta, A. (2017). Longitudinal stent deformation during coronary intervention: A report of three cases. IHJ Cardiovascular Case Reports (CVCR), 1(2), 68-71. https://doi.org/10.1016/j.ihjccr.2017.08.005

Zou, Q., Xue, W., Lin, J., Fu, Y., Guan, G., Wang, F., \& Wang, L. (2016). Mechanical characteristics of novel polyester/NiTi wires braided composite stent for the medical application. Results in Physics, 6, 440-446. https://doi.org/10.1016/j.rinp.2016.07.007 